\title{
Drug susceptibility in emerging fungal infections: tests with fluconazole, itraconazole, and amphotericin $\mathrm{B}^{*}$
}

\author{
Vanessa da Silva Fay ${ }^{1}$ \\ Stela Maris Bottin Gonçalves ${ }^{2}$ \\ Renan Rangel Bonamigo ${ }^{1}$
}

\author{
Diana Mara Garcia Rodrigues ${ }^{2}$ \\ Tatiana Schaffer Gregianini ${ }^{2}$
}

DOI: http:/ / dx.doi.org/10.1590/abd1806-4841.20187364

\begin{abstract}
The number of new cases of emerging fungal infections has increased considerably in recent years, mainly due to the large number of immunocompromised individuals. The objective of this study was to evaluate the susceptibility of emerging fungi to fluconazole, itraconazole and amphotericin B by disk diffusion method. In 2015, 82 emerging fungi were evaluated in IPB-LACEN/RS and 13 (15.8\%) were resistant: 10/52 were from superficial mycoses and 3/30 from systemic mycoses. The data from the study point to the need for permanent vigilance regarding the careful evaluation in the prescription and clinical and laboratory follow-up of patients affected by fungal infections.
\end{abstract}

Keywords: Antifungal agents; Drug resistance; Mycology

Fungal resistance has been increasing in many areas throughout the world and determining the sensitivity profile of the agents allows for a safe practice. Among the many methods available to evaluate the sensitivity, the disk diffusion method (DD) is affordable and easily reproducible. ${ }^{1,2}$ We conducted a study to evaluate the susceptibility of emerging fungi to certain antifungals in samples from the Laboratory of Mycology of the Laboratório Central do Estado do Rio Grande do Sul (Lacen-RS), after approval by the Ethics Committee in Research of the Universidade Federal de Ciências da Saúde, Porto Alegre and of the Fundação Estadual de Produção e Pesquisa em Saúde. Were defined as emergent the saprophytic fungi capable of causing infections. Such diseases are recently or recurrently recognized in the literature, with increasing incidences and tendency to a wide geographical distribution.

The determination of the susceptibility to the antifungal was tested with DD to fluconazole, itraconazole and amphotericin B from samples (from 2015) kept in agar and periodically reseeded. ${ }^{3}$ The samples were collected from patients with clinical signs of emerging mycoses and were immediately cultivated and analyzed to avoid becoming less virulent due to frequent seeding, such as what occurs with Paracoccidioides brasiliensis. ${ }^{4}$ cellular suspensions were prepared in saline solution $(\mathrm{NaCl} 0.85 \%)$ and adjusted to $10^{6}$ cells/mL, corresponding to the 0.5 MacFarland scale. Part of the inoculum was removed with the immersion of a sterile swab and seeded in Petri plaques containing agar Mueller-Hinton (Oxoid Hampshire, England) supplemented with $2 \%$ glucose. The disks with fluconazole $(25 \mu \mathrm{g})$, itraconazole $(10 \mu \mathrm{g})$ and amphotericin B $(100 \mu \mathrm{g})$ were applied to the agar surface and incubated at $35^{\circ} \mathrm{C}$ for 24 to 48 hours. Quality control of the tests was performed with strains of Candida parapsilosis ATCC 22019 and Candida albicans ATCC 14053.

Of the 82 samples of emerging fungi tested, 57 were isolated in female patients and 25 in male patients, with a mean age of 43 years. In cases with resistance to the antifungals, mean age was of 69 years. We observed 10 (19.2\%) resistant fungal strains among the samples of 52 superficial mycoses and three (10\%) resistant strains among the samples from 30 deep mycoses, with a total of $13(15.8 \%)$ resistant strains out of the 82 analyzed. The susceptibility profile according to the antifungal agents tested is shown in table 1, related to the gender and HIV infection status. There were no significant differences (using the chi-square test and considering $\mathrm{p}<0.05$ ) between these relationships. Fluconazole was the antifungal to which the largest number of strains was resistant (9/82). The resistance

Received 27 June 2017.

Accepted 20 November 2017.

* Work conducted at the Instituto de Pesquisas Biológicas/Laboratório Central (IPB-Lacen) da Secretaria de Saúde do Estado do Rio Grande do Sul, Porto Alegre (RS), Brazil.

Financial support: Programa de Apoio ao Desenvolvimento Científico e Tecnológico (PADCT).

Conflict of interest: None.

Program of Post-Graduation in Pathology, Universidade Federal de Ciências da Saúde de Porto Alegre, Porto Alegre (RS), Brazil.

Instituto de Pesquisas Biológicas/Laboratório Central (IPB-Lacen) da Secretaria de Saúde do Estado do Rio Grande do Sul, Porto Alegre (RS), Brazil.

MAILING ADDRESS:

Vanessa da Silva Fay

E-mail: nessabiosinos@yahoo.com.br 


\begin{tabular}{|c|c|c|c|c|c|c|}
\hline \multirow[b]{3}{*}{$\begin{array}{l}\text { Superficial } \\
\text { mycosis * }\end{array}$} & \multicolumn{2}{|c|}{ Fluconazole } & \multicolumn{2}{|c|}{ Itraconazole } & \multicolumn{2}{|c|}{ Amphotericin B } \\
\hline & $S$ (n) & $\mathrm{R}(\mathrm{n})$ & $S^{*}(n)$ & $R^{*}(n)$ & $S^{*}(n)$ & $R^{*}(n)$ \\
\hline & 45 & 6 & 42 & 3 & 50 & 1 \\
\hline $\begin{array}{l}\text { Systemic } \\
\text { mycosis ** }\end{array}$ & 24 & 3 & 22 & 0 & 30 & 0 \\
\hline $\begin{array}{l}\text { Male } \\
\text { gender }\end{array}$ & 20 & 2 & 21 & 0 & 25 & 0 \\
\hline $\begin{array}{l}\text { Female } \\
\text { gender }\end{array}$ & 49 & 7 & 43 & 3 & 55 & 1 \\
\hline HIV - & 66 & 8 & 60 & 3 & 76 & 1 \\
\hline $\mathrm{HIV}+$ & 31 & 1 & 4 & 0 & 4 & 0 \\
\hline
\end{tabular}

* Skin, nails

** Mucous membranes (except if isolated only on the oral, genital, anal mucosa), cerebrospinal fluid, bronchoalveolar fluid, pleural fluid, sputum, blood, liver, lymph node, bone.

$\mathrm{R}=$ resistant; $\mathrm{S}=$ sensitive.

found in systemic mycoses was of Cryptococcus neoformans to fluconazole. The complete results of the susceptibility of the species are shown in table 2.

We demonstrated in this study that the susceptibility to the antifungals tested was not influenced by the site of the lesion nor by HIV infection, but by age - the resistant cases were in older individuals. The larger number of cases of superficial mycoses occurred in women, suggesting a higher exposure and seeking of medical assistance. C. albicans continues to be one of the main causes for invasive infections but, the incidence of $C$. parapsilosis has grown significantly. ${ }^{5}$ Resistance to amphotericin B was the lowest among the drugs tested and was actually related to a little cited species in the literature, Candida famata. ${ }^{6}$ Studies with C. albicans samples from patients with recurrent infections showed that the resistance to fluconazole occurred in the same infections where the previous species were susceptible. This confirms data from other studies in which the strains changed over the course of exposure to the patient, characterizing acquired resistance. ${ }^{7,8}$ Pasqualotto $e t$ al. warned about this phenomenon, particularly regarding the use of fluconazole for the management of Candida glabrata infections. According to these authors, prophylaxis should be avoided in situations of lower risk of systemic infection. In general, for all the Candida species evaluated in our study, the resistance rates found were higher than those found by other authors. Such discrepancy could be associated to high recurrence rates of candidiasis and to the profile of our institution, responsible for the epidemiological surveillance

\begin{tabular}{|c|c|c|}
\hline \multicolumn{3}{|c|}{$\begin{array}{l}\text { TABLE 2: Emerging species and resistance } \\
(\mathrm{n}=82, \text { Lacen/RS, 2015) }\end{array}$} \\
\hline Species & Antifungal & Resistance (n) \\
\hline \multirow{3}{*}{ Candida albicans $(\mathrm{n}=25)$} & Amphotericin B & 0 \\
\hline & Fluconazole & 3 \\
\hline & Itraconazole & 2 \\
\hline \multirow{3}{*}{ Candida spp. ${ }^{*}(\mathrm{n}=5)$} & Amphotericin B & 0 \\
\hline & Fluconazole & 1 \\
\hline & Itraconazole & 0 \\
\hline \multirow{3}{*}{$\begin{array}{l}\text { Candida parapsilosis } \\
(\mathrm{n}=18)\end{array}$} & Amphotericin B & 0 \\
\hline & Fluconazole & 1 \\
\hline & Itraconazole & 1 \\
\hline \multirow{3}{*}{$\begin{array}{l}\text { Candida guillermondii } \\
(\mathrm{n}=2)\end{array}$} & Amphotericin B & 0 \\
\hline & Fluconazole & 0 \\
\hline & Itraconazole & 0 \\
\hline \multirow{3}{*}{ Candida tropicalis $(\mathrm{n}=2)$} & Amphotericin B & 0 \\
\hline & Fluconazole & 1 \\
\hline & Itraconazole & 0 \\
\hline \multirow{3}{*}{$\begin{array}{l}\text { Candida colliculosa } \\
(\mathrm{n}=1)\end{array}$} & Amphotericin B & 0 \\
\hline & Fluconazole & 0 \\
\hline & Itraconazole & 0 \\
\hline \multirow{3}{*}{ Candida famata $(\mathrm{n}=1)$} & Amphotericin B & 1 \\
\hline & Fluconazole & 0 \\
\hline & Itraconazole & 0 \\
\hline \multirow{3}{*}{ Candida lipolytica $(\mathrm{n}=1)$} & Amphotericin B & 0 \\
\hline & Fluconazole & 0 \\
\hline & Itraconazole & 0 \\
\hline \multirow{3}{*}{ Candida kefyr $(\mathrm{n}=1)$} & Amphotericin B & 0 \\
\hline & Fluconazole & 0 \\
\hline & Itraconazole & 0 \\
\hline \multirow{3}{*}{$\begin{array}{l}\text { Cryptococcus neoformans } \\
(\mathrm{n}=26)\end{array}$} & Amphotericin B & 0 \\
\hline & Fluconazole & 3 \\
\hline & Itraconazole & 0 \\
\hline
\end{tabular}

* The identification was not possible in 5 cases.

of the state of Rio Grande do Sul, dealing with the confirmation of difficult-to-manage cases.

This study aims to alert about the importance of the thorough evaluation of the use of antifungals in clinical practice. The tests to define fungal susceptibility to the treatments are tools for knowing the changes in the behavior of emerging fungi and the epidemiological profile of fungal infections. 


\section{REFERENCES}

1. Gomes CL, Cavalcante JE, Cunha FA, Amorim LN, Menezes EA. Identificação e perfil de sensibilidade de Candida spp. isoladas de urina de pacientes com candidúria em Iguatu-Ceará. Rev bras anal Clin. 2010; 42:223-5.

2. Campana EH, Carvalhaes CG, Nonato B, Machado AM, Gales AC. Comparison of M.I.C.E. and Etest with CLSI agar dilution for antimicrobial susceptibility testing against oxacillin-resistant Staphylococcus spp. PLoS One. 2014;9:e94627.

3. Clinical and Laboratory Standards Institute. Reference method for disk diffusion susceptibility testing of yeasts. Approved standard M-44A2. Wayne, Pa: Clinical and Laboratory Standards Institute; 2009.

4. Macoris SA, Sugizaki MF, Peraçoli MT, Bosco SM, Hebeler-Barbosa F, Simões $\mathrm{LB}$, et al. Virulence attenuation and phenotypic variation of Paracoccidioides brasiliensis isolates obtained from armadillos and patients. Mem Inst Oswaldo Cruz. 2006;101:331-4.
5. Lagrou K, Verhaegen J, Peetermans WE, De Rijdt T, Maertens J, Van Wijngaerden E. Fungemia at a tertiary care hospital: incidence, therapy, and distribution and antifungal susceptibility of causative species. Eur J Clin Microbiol Infect Dis. 2007;26:541-7

6. Beyda ND, Chuang SH, Alam MJ, Shah DN, Ng TM, McCaskey L, et al. Treatment of Candida famata bloodstream infections: case series and review of the literature. J Antimicrob Chemother. 2013;68:438-43.

7. Rodríguez-Tudela JL, Arendrup MC, Cuenca-Estrella M, Donnelly JP, Lass-Flörl C. EUCAST breakpoints for antifungals. Drug News Perspect. 2010;23:93-7.

8. Pasqualotto AC, Zimerman RA, Alves SH, Aquino VR, Branco D, Wiltgen D,et al. Take control over your fluconazole prescriptions: the growing importance of Candida glabrata as an agent of candidemia in Brazil. Infect Control Hosp Epidemiol. 2008;29:898-9.

$\begin{array}{ll}\text { Vanessa da Silva Fay } & \text { (iD) ORCID 0000-0002-0523-4565 } \\ \text { Diana Mara Garcia Rodrigues } & \text { (iD) ORCID 0000-0003-3150-8205 } \\ \text { Stela Maris Bottin Gonçalves } & \text { (D) ORCID 0000-0001-5346-742X }\end{array}$

Tatiana Schaffer Gregianini

(iD) ORCID 0000-0002-9912-9060

Renan Rangel Bonamigo
(iD) ORCID 0000-0003-4792-8466

How to cite this article: Fay VS, Rodrigues DMG, Gonçalves SMB, Gregianini TS, Bonamigo RR. Drug susceptibility in emerging fungal infections: tests with fluconazole, itraconazole, and amphotericin B. An Bras Dermatol. 2018;93(3):462-4. 